\title{
Dielectric Proprieties Determination of High Density Polyethylene (HDPE) by Dielectric Spectroscopy
}

\author{
T. Seghier and F. Benabed
}

\begin{abstract}
Dielectric methods are now widely used to study and characterization of organic or inorganic insulators, because of the wide range of frequency that can be studied with excellent resolution. In this article, we present and analyze the dielectric properties of high-density polyethylene (HDPE) by dielectric spectroscopy, we present permittivity, loss factor and conductivity data at frequency range of $10-2 \mathrm{~Hz}$ to $1 \mathrm{MHz}$ over temperature range of $-60^{\circ} \mathrm{C}$ to $60^{\circ} \mathrm{C}$.
\end{abstract}

Index Terms-Dielectric proprieties, high density polyethylene, spectroscopy, temperature.

\section{INTRODUCTION}

The isolation function is critical because it is one of the basic operating conditions of electrical energy (production, transmission and distribution). Given the importance of insulation systems in the life of high and medium voltage equipment, we must study and understand the mechanisms that are responsible for the degradation of these systems.

Polyethylene is the most widely used insulation materials because of its electrical and mechanical properties which have made it a preferred material for cable insulation in high voltage [1]. There are several types of polyethylene, which are distinguished by their chemical structure.

In this paper, we present the dielectric proprieties of high density polyethylene HDPE which is obtained at low pressure, and is a linear, crystalline and rigid polymer.

These proprieties such as permittivity $\varepsilon$, conductivity $\sigma$ and loss factor $\tan \delta$ are measured by dielectric relaxation spectroscopy (DRS) in the frequency range $\left(10^{-2}-10^{6}\right) \mathrm{Hz}$ at temperature between -60 and $60{ }^{\circ} \mathrm{C}$.

\section{DIELECTRIC SPECTROSCOPY}

Dielectric spectroscopy, which is based on the measurement of current and voltage (amplitude and phase $\mathrm{AC}$ system) is widely used to study the dielectric properties of polymers such as $\left(\varepsilon^{\prime}, \tan \delta \ldots\right)$ [2], [3].

Its scope very high frequencies $(\sim \mathrm{THz})$ which are used to characterize all atomic phenomena and electronic polarization, and down to very low frequencies range $(\sim \mathrm{MHz})$ to characterize the state of different interfaces which may exist between insulation components [4].

Under an alternative (ac) sinusoidal supplied voltage, the real part of permittivity and loss factor is computed using the

Manuscript received February 15, 2014; revised December 7, 2014.

The authors are with the Department of Electrical Engineering, Amar Telidji University, Laghouat, PO Box 37G, Guardaia road, Laghouat 03000, Algeria (e-mail: t.seghier@lagh-univ.dz, benabed_fa@yahoo.fr). following equations:

$$
\begin{gathered}
\varepsilon^{\prime}=\frac{C_{p} d}{\varepsilon_{0} A} \\
\tan \delta=\frac{\epsilon^{\prime \prime}}{\varepsilon^{\prime}}=\frac{1}{R_{p} C_{p} \omega}
\end{gathered}
$$

where $\varepsilon_{0}$ is the vacuum permittivity, $d$ the thickness of the sample polymer, $A$ the electrode area and $\omega$ the angular frequency, $C_{p}$ and $R_{p}$ are the capacitance and the resistance measurements.

The static (dc) conductivity has been derived from the (ac) conductivity measurements at low frequency:

$$
\sigma_{a c}(\omega)=\omega \varepsilon_{0} \varepsilon^{\prime \prime}(\omega)=\sigma_{d c}+K \omega^{n}
$$

where $K$ is an empiric parameter and $\mathrm{n}$ represents the high frequency slope of the (ac) conductivity from 0 to 1 [5].

\section{EXPERIMENTAL METHOD}

The material used in this study is a High density Polyethylene (HDPE). As shown in Fig. 1, the specimens used in measurements are gold coated on each face to obtain circular electrodes of $16 \mathrm{~mm}$ in diameter and the thickness of the sample is $1 \mathrm{~mm}$. Samples are prepared in laboratory to analyze partial discharge phenomena [6], [7].

Measurements of the real part of the permittivity, the loss factor and the conductivity for polymer samples were performed under $\mathrm{AC}$ voltage $1 \mathrm{~V}$ in the frequency range $10^{-2}$ $\mathrm{Hz}$ to $1 \mathrm{MHz}$ using a Broad Band Dielectric Controller (Novocontrol), Alpha, Beta Analyzer.

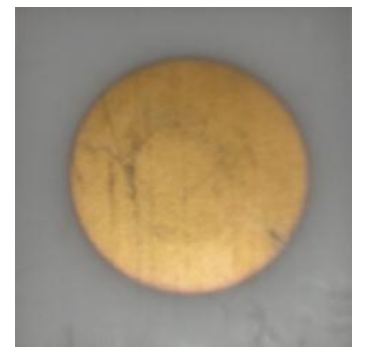

Fig. 1. Picture of the solid insulation sample HDPE.

\section{RESULTS AND DISCUSSION}

The experimental results of the loss factor and real part of the permittivity versus frequency and temperature for the samples of HDPE are illustrated in Fig. 2 and Fig. 3.

From Fig. 2, it is clear that the dielectric constant $\varepsilon$ ' is a slight function of frequency with a slight decrease as frequency increases. Dielectric constant is higher at low 
frequencies; the decrease with temperature is attributed at the temperature-dependent of the specific volume of HDPE [8].

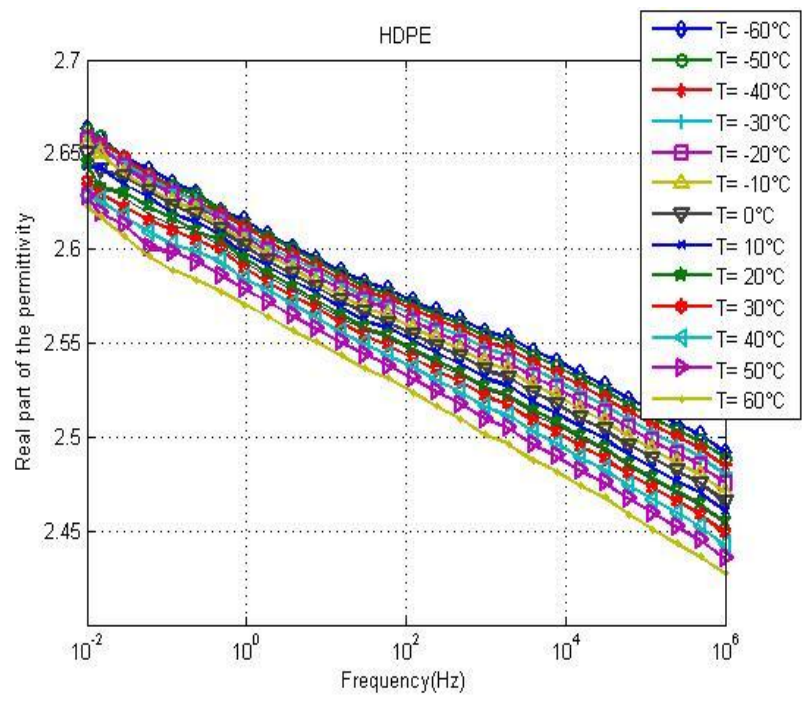

Fig. 2. The real part of the permittivity $\varepsilon^{\prime}$ of HDPE as function of frequency for different temperature.

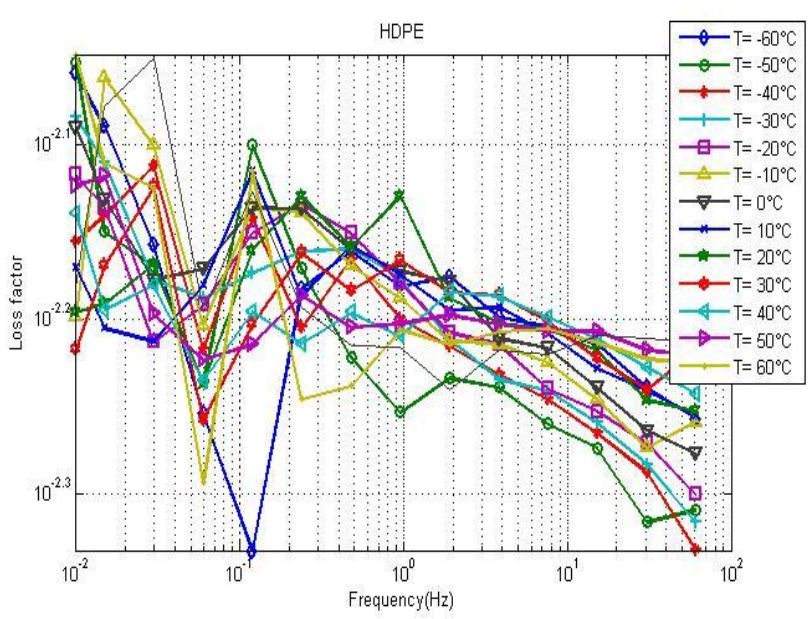

(a) Frequency range $10^{-2}$ to $10^{2} \mathrm{~Hz}$

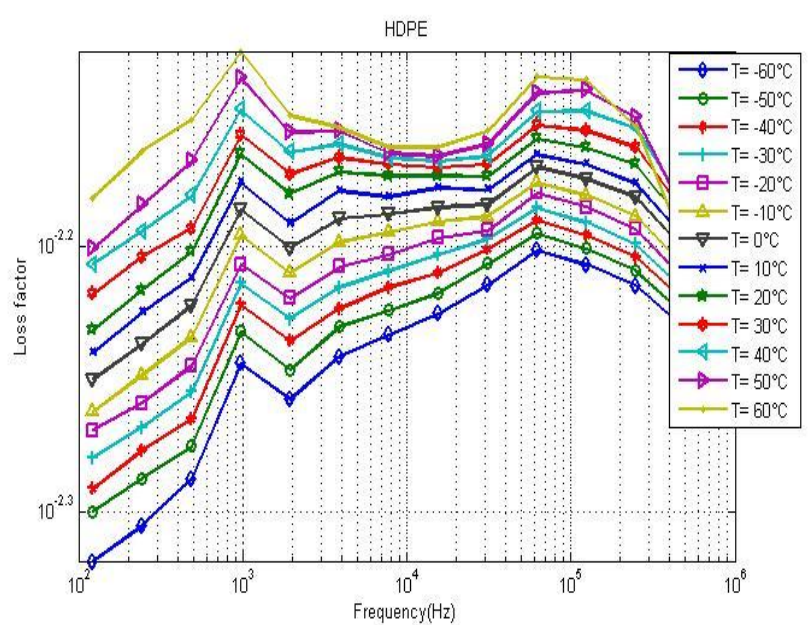

(b) Frequency range $10^{2}$ to $10^{6} \mathrm{~Hz}$

Fig. 3. Loss factor of HDPE as function of frequency for different temperature.

In contrast from Fig. 3, the loss factor varies with temperature more vigorously at lower temperature due to change in structure. We know that the polyethylene has a very low glass transition temperature, which lies in the region where the fluctuations are observed [9].
The variation of $\varepsilon^{\prime}$ and $\tan \delta$ with $\omega$, including the effect of DC conductivity, is shown in Fig. 4.

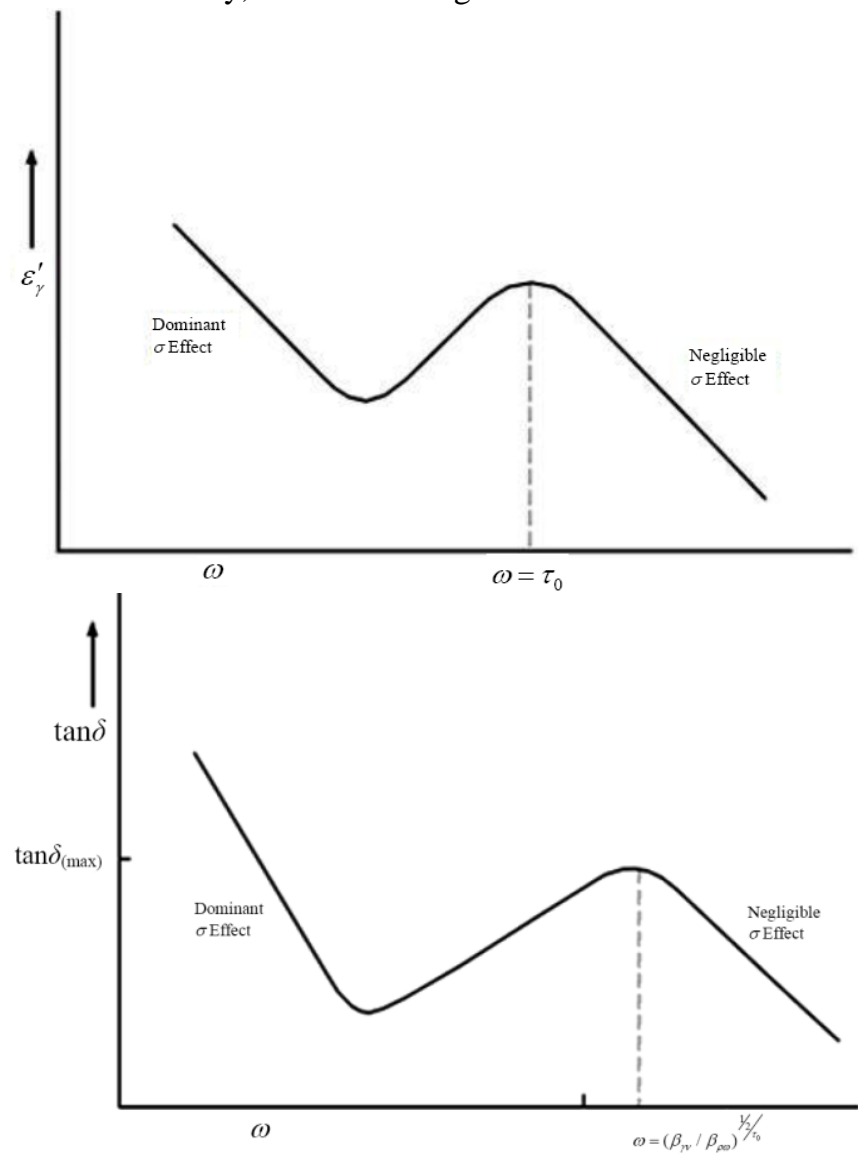

Fig. 4. Permittivity $\varepsilon^{\prime}$ and loss factor as functions of pulsation taking into account the effect of dc conductivity [10].

An important increase in values of $\varepsilon^{\prime}$ and $\tan \delta$ at low frequencies and high temperature is observed. This reflects conductivity effects due to free charge motion within the material [11].

For very low frequencies there is enough time for these ions to build up at the interface between the material and the electrodes giving rise to space charge polarization.

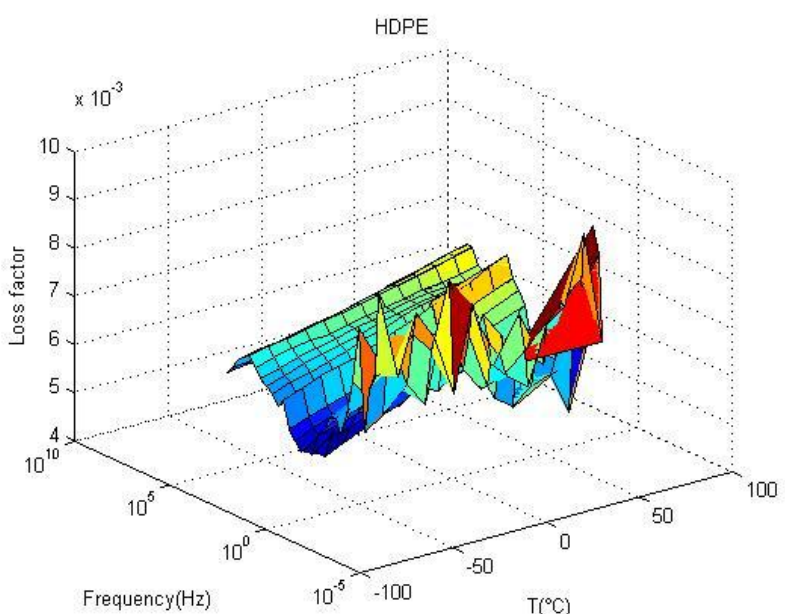

Fig. 5. Loss factor of HDPE as function of frequency and temperature.

For more details, we present the variations of the real part of the permittivity $\varepsilon^{\prime}$, the Loss factor and the real part of the conductivity $\sigma^{\prime}$ as a function of frequency and temperature in 3D curves, on Fig. 5 and Fig. 6 respectively. 


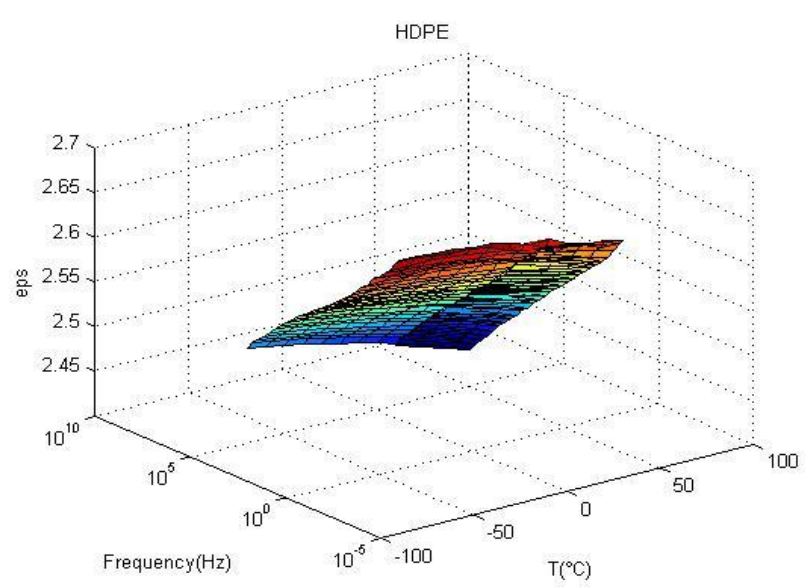

Fig. 6. The real part of the permittivity $\varepsilon^{\prime}$ of HDPE as of frequency and temperature.

Theatrically a non-polar polymer such as HDPE should show only $\alpha$-dispersion since the only motion that can occur is due to the main chain at the glass transition temperature, but from Fig. 5, two loss regions are observed in HDPE: the exact temperature and frequency can be determined by recognizing the morphology and impurity for the samples [9].

The loss peaks may due to the presence of polar additives or other impurity.

The dielectric loss of HDPE at different temperature is almost constant because HDPE is thermally stable than other polymers [6]. But the peaks observed in Fig. 3 and Fig. 6 are related to the orientation-induced modifications of the structural and morphological parameters [12].

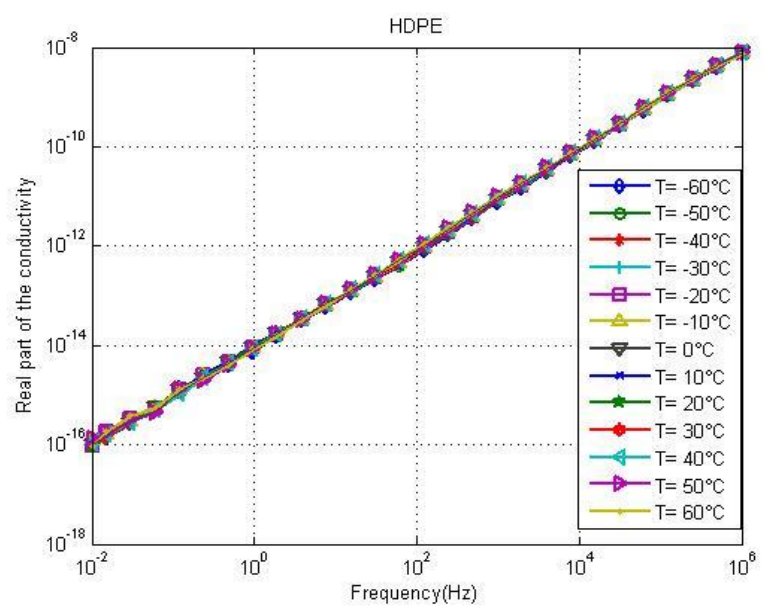

Fig. 7. The real part conductivity $\sigma^{\prime}$ as function of frequency for different temperature.

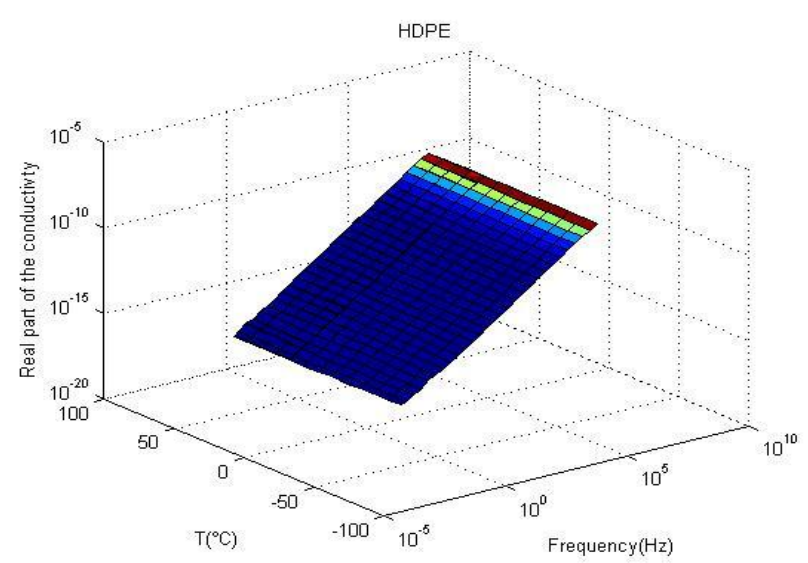

Fig. 8. the real part Conductivity $\sigma^{\prime}$ as function of frequency and temperature
From Fig. 7 and Fig. 8, it is clear that conductivity increases with frequency, while the temperature has no effect.

It is generally believed that conductivity and the relaxation process contribute to the increase in both real part of permittivity and the loss factor on decreasing frequencies [13].

\section{CONCLUSION}

In this work we have presented results of electrical and dielectric studies in polyethylene high density by using of dielectric relaxation spectroscopy (DRS in frequency range $10^{-2}-106 \mathrm{~Hz}$ and temperature between $-60^{\circ} \mathrm{C}$ and $60^{\circ} \mathrm{C}$. The use of dielectric spectroscopy technique allowed observing the dielectric behavior of HDPE samples in the low frequency region and the results of DRS were analyzed within the permittivity formalism.

The experimental results indicate that the decrease in dielectric constant with frequency and temperature for HDPE which is a non-polar polymer, is described to the weak polar nature of this polymer, some loss peak are observed as a result of the presence of additive and other impurities.

The results also show that the decreasing in the dielectric constant with increasing frequency is due to the DC conductivity contribution.

\section{ACKNOWLEDGMENT}

This work was performed in the laboratory OF LAPLACE at the Paul Sabatier University of Toulouse, The authors would like to thank the personal for their support in materials as well as all the collaborators of this work.

\section{REFERENCES}

[1] J. P. van Bolhuis, E. Gulski, and J. J. Smit, "Monitoring and Diagnostic of Transformer Solid Insulation,"IEEE Transactions on Power Delivery, vol. 17, no. 2, April 2002.

[2] E. Dantras, E. Dudognon, A. Bernès, and C. Lacabanne, "Study of polymers with various chemical structures and chain architectures by thermally stimulated currents and broadband dielectric spectroscopy," IEEE Transactions on Dielectrics and Electrical Insulation, vol. 11, pp. 312-319, April 2004.

[3] O. S. Gene, S. M. Lebedev, Y. P. Pokholkov, S. N. Tkachenko, V. A. Volokhin, and E. I. Cherkashina, "Study of dielectric relaxation spectra of composite materials by the dielectric spectroscopy method," in Proc. International Symposium on Electrical Insulating Materials, June 5-9, 2005, Kitakyushu, Japan.

[4] J. R. Macdonald, "Impedance spectroscopy," Annals of Biomedical Engineering, vol. 20, pp. 289-305, 1992.

[5] R. Khazaka, M.-L. Locatelli, and S. Diaham, "Conductivity spectroscopy and conduction current measurements of polyimide thin films during high temperature aging," IEEE, pp. 107-108, 2011.

[6] M. A. Hameed and B. A. Shuja-Aldeen, "Dielectric proprieties of commercial non-polar polymers," Journal of Zankoy Sulaimani, vol. 11, no. 1, part A, pp. 1-8, 2008.

[7] T. Seghier, "Etude des décharges partielles et leurs influences sur l'apparition des arborescences dans la couche isolante des câbles haute tension," doctoral thesis, University of Biskra, Algeria,2011

[8] T. Seghier and D. Mahi, "Investigation into partial discharge dependence in air gaps between high density polyethylene tapes,"Acta Electrotehnica, vol. 49, no. 1, pp. 3-13, 2008.

[9] G. G. Raju, Dielectrics in Electric Fields, New York: Marcel Dekker Inc., 2003, pp. 119-121.

[10] K. K. Chi, "Dielectric phenomena in solids: with emphasis on physical concepts of electronic processes," Elsevier Academic Press, USA, 2004, pp. 94-97.

[11] A. Medjdoub, A. Boubakeur, and T. Lebey, "Dielectric spectroscopy analysis behavior of low density polyethylene," in Proc. Annual Report Conference on Electrical Insulation Dielectric Phenomena, 2008, pp. 517-520. 
[12] A. Medjdoub, A. Boubakeur, and T. Lebey, "Broad band dielectric investigation of cross-linked polyethylene use as electrical insulation on underground power cables," in Proc. Annual Report Conference on Electrical Insulation and Dielectric Phenomena, 2010.

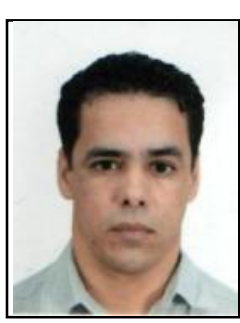

Tahar Seghier was born on the $25^{\text {th }}$ of January 1971 in Laghouat, Algeria. He received the electrical engineering degree in electrical machines form Amar Telidji University of Laghouat (UATL), Algeria, in 1996 and the magister degree in electrical engineering materials from UATL in 2001. He joined the research Laboratory (Laboratoire d'études et Développement des Matériaux Semi-conducteurs et Diélectriques) at UATL in 2001, where he is now the head of Materials for Energy Conversion Research Team. His research interests include materials characterization aging, discharge phenomena modeling in dielectrics, high voltage and electromagnetic compatibility. He is working as an associate professor at the electrical engineering department of UATL since 2011.

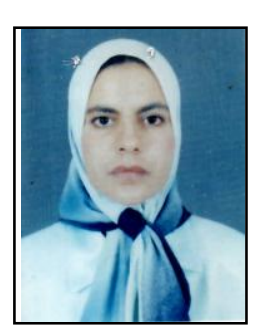

Fadila Benabed was born on the $19^{\text {th }}$ of December 1973 in Laghouat, Algeria. She received the electrical engineering degree in electrical machines form Amar Telidji University of Laghouat (UATL), Algeria, in 1996 and the magister degree in dielectric materials from UATL in 2012. She joined the research Laboratory (Laboratoire d'études et Développement des Matériaux Semi-conducteurs et Diélectriques) at UATL in 2012. Her research interests include materials characterization aging, discharge phenomena modeling in dielectrics and high voltage. She is working as an associate professor at the electrical engineering department of UATL since 2011. 